\title{
Colonic hydrogen absorption: quantification of its effect on hydrogen accumulation caused by bacterial fermentation of carbohydrates
}

\author{
Heinz F Hammer
}

\begin{abstract}
The aim of the study was to assess (quantitatively) colonic hydrogen absorption. Hydrogen volumes in flatus and breath were measured over periods of six hours in normal subjects during fasting and after ingestion of the nonabsorbable carbohydrate lactulose to simulate the effect of fermentable dietary fibres. If less than $76 \mathrm{ml} / 6 \mathrm{~h}$ of hydrogen accumulated in the colon then all of it was absorbed, as suggested by the intercept of the regression line of the correlation between hydrogen volumes in flatus and breath after ingestion of lactulose. As total flatus volume increased, efficiency of colonic hydrogen absorption decreased from $90 \%$ to $20 \%$. The positive correlation between hydrogen volumes of flatus and breath showed that the eightfold interindividual differences in flatus volume after ingestion of $12.5 \mathrm{~g}$ of lactulose were caused by differences in bacterial net gas production, not gas absorption. Differences in colonic gas emptying rate are the consequence rather than the cause of interindividual differences in flatus volume. In conclusion: (1) colonic hydrogen absorption is highly effective at low colonic hydrogen accumulation rates, but not at higher accumulation rates; (2) ineffective colonic gas absorption is the consequence and not the cause of high colonic gas accumulation rate after ingestion of non-absorbable carbohydrates; and (3) future therapeutic approaches to the large interindividual variability in colonic gas accumulation after ingestion of poorly absorbable fermentable carbohydrates, such as some kinds of dietary fibres, should be directed towards altering colonic bacterial metabolism.
\end{abstract}

(Gut 1993; 34: 818-822)

Symptoms related to accumulation of intestinal gas are frequent complaints of patients attending physicians and have a wide variety of diagnoses including gastrointestinal and non-gastrointestinal diseases, dietary habits, and side effects of various drugs. ${ }^{1}$ Although one reason for accumulation of intestinal gas is increased gas production due to bacterial metabolism of carbohydrates, ${ }^{23}$ which are a readily available substrate for gas production both in malabsorptive diseases ${ }^{4}$ and in normal people, ${ }^{56}$ other factors such as decreased intestinal absorption of gas theoretically have an important role. Factors influencing intestinal gas absorption have been described qualitatively, ${ }^{7-9}$ but the extent to which gas absorption has a quantitative role in reducing colonic gas accumulation has not been assessed previously. Also, there is increasing awareness of the beneficial effects of including fibres, which are poorly absorbable carbohydrates, into diet. ${ }^{10} 11$ Some of the dietary fibres are readily fermented by colonic bacteria, thereby providing to the general population a substrate for gas production and symptoms related to gas. ${ }^{6}$

The aim of this study was to quantitatively assess colonic hydrogen absorption in normal subjects during fasting to obtain baseline values, and after ingestion of lactulose to simulate gas production caused by the ingestion of dietary fibres.

\section{Method}

SUBJECTS

Ten healthy non-smokers (eight men, two women, mean age: 29 (SEM 2) years, range 24-45 years) with no history of recent gastrointestinal disease or milk intolerance and no clinical signs of disturbed intestinal transit were studied after they gave informed consent. They had not received antibiotics for at least four weeks before the study. Table 1 gives information on age, sex, height, weight, and body surface area of the subjects. There were no dietary restrictions imposed the day before the study. The studies were approved by the ethics commitee.

\section{STUDY DESIGN}

Subjects reported to the study centre after an overnight fast of at least 12 hours. Each subject was studied on two separate occasions. Data were analysed from two subjects receiving $25 \mathrm{~g}$ of lactulose and eight subjects receiving $12.5 \mathrm{~g}$ of lactulose dissolved in $250 \mathrm{ml}$ of water. The dose of lactulose was reduced because of development of diarrhoea in three out of five subjects receiving $25 \mathrm{~g}$ of lactulose, which caused clogging of the gas collection device and made flatus collection

TABLE I Study subjects

\begin{tabular}{lllll}
\hline Subject & AgeSex & $\begin{array}{l}\text { Height } \\
(\mathrm{cm})\end{array}$ & $\begin{array}{l}\text { Weight } \\
(\mathrm{kg})\end{array}$ & $\begin{array}{l}\text { Surface area } \\
\left(\boldsymbol{m}^{2}\right)\end{array}$ \\
\hline 1 & $31 \mathrm{M}$ & 180 & 84 & $2 \cdot 03$ \\
2 & $26 \mathrm{M}$ & 183 & 90 & $2 \cdot 12$ \\
3 & $23 \mathrm{M}$ & 180 & 79 & 1.98 \\
4 & $25 \mathrm{M}$ & 179 & 82 & $2 \cdot 00$ \\
5 & $24 \mathrm{M}$ & 183 & 82 & $2 \cdot 04$ \\
6 & $28 \mathrm{M}$ & 173 & 58 & 1.69 \\
7 & $28 \mathrm{M}$ & 178 & 68 & 1.84 \\
8 & $35 \mathrm{M}$ & 163 & 54 & 1.57 \\
9 & $45 \mathrm{~W}$ & 157 & 50 & 1.48 \\
10 & $24 \mathrm{~W}$ & 171 & 68 & 1.79 \\
\hline
\end{tabular}

$\mathrm{M}=\operatorname{man}, \mathrm{W}=$ woman 
invalid. These three subjects were excluded from the study. None of the subjects whose data were included had diarrhoea during the study period. In the 10 subjects who were included, the study was repeated on a second day without ingestion of lactulose. Studies on a subject were separated by at least one week.

MEASUREMENT OF TOTAL VOLUME OF FLATUS AND HYDROGEN VOLUME IN FLATUS

Just before the ingestion of lactulose, a polyvinyl catheter was inserted into the rectum and attached by a three way stopcock to a $100 \mathrm{ml}$ glass syringe for collection of flatus. In a preliminary study a subject was seated in a water bath to see whether any gas escaped collection by the rectal catheter, as shown by gas bubbles originating from the anus. This experiment showed that the flatus collection device did not leak any gas. Cumulative total flatus volume was measured at 30 minute intervals for six hours. After dilution with air to a hydrogen concentration below 200 parts per million (ppm), flatus was analysed for hydrogen concentration with a $12 \mathrm{i}$ microlyzer (Quintron Instrument Co, Milwaukee, USA). Serial dilution steps were performed with a three way stopcock connected to the syringe that contained the hydrogen. The dilution process was validated before the experiments by diluting samples of standard gas containing $208600 \mathrm{ppm}$ and $1560 \mathrm{ppm}$ of hydrogen (Quingas Calibrating Standard, Quintron Instrument Co, Milwaukee, USA). Flatus hydrogen volume was calculated by multiplying total flatus volume and flatus hydrogen concentration.

\section{MEASUREMENT OF HYDROGEN CONCENTRATION IN} BREATH

End expiratory air was collected before starting the study, and every 30 minutes for the duration of the study in a Quintron Gasampler (Quintron Instrument $\mathrm{Co}$, Milwaukee, USA). This consists of a discard bag $(500 \mathrm{ml})$ to collect dead space ventilation and a collection bag constructed from a plastic film laminated aluminium foil $(750 \mathrm{ml})$, which collects alveolar ventilation. Gas $(20 \mathrm{ml}$ of samples) that was removed from the collection bag was analysed for hydrogen concentration.

MEASUREMENT OF BREATH MINUTE VOLUME

In four subjects mean breath minute volume was calculated from between three to nine quantitative five minute breath collections. Mean body surface area in these four subjects was 1.86 (SEM $0 \cdot 1) \mathrm{m}^{2}$ as compared with $1 \cdot 85(0 \cdot 1) \mathrm{m}^{2}$ in all of

TABLE II Hydrogen volume in flatus and breath in normal subjects during fasting and after ingestion of 12.5 or $25 \mathrm{~g}$ of lactulose

\begin{tabular}{llll}
\hline & $\begin{array}{l}\text { Breath } \\
\text { hydrogen } \\
(\text { ml/6h) } \\
\text { Mean }(S E M)\end{array}$ & $\begin{array}{l}\text { Total flatus } \\
\text { (ml/6h) } \\
\text { Mean }(S E M)\end{array}$ & $\begin{array}{l}\text { Flatus } \\
\text { hydrogen } \\
(\text { mll6h }) \\
\text { Mean }(S E M)\end{array}$ \\
\hline $\begin{array}{l}\text { Fasting }(\mathrm{n}=10) \\
12 \cdot 5 \mathrm{~g} \text { lactulose } \\
(\mathrm{n}=8)\end{array}$ & $14(2)$ & $100(8)$ & $5(1)$ \\
$\begin{array}{c}25 \mathrm{~g} \text { lactulose } \\
(\mathrm{n}=2)\end{array}$ & $89(12)$ & $430(83)$ & $123(56)$ \\
\hline
\end{tabular}

the 10 subjects. This difference was not statistically significant. Breath was collected in a Douglas plastic bag (W E Collins, Braintree, Massachusetts, USA) connected to the mouth of the subjects with a three way valve. Quantitative breath collection was started five minutes before measurement of breath hydrogen concentration was due according to our protocol, and finished immediately before end expiratory breath hydrogen analysis was performed. Gas volume collected in the bag was measured with a chain compensated gasometer (W E Collins, Braintree, Massachusetts, USA) and hydrogen concentration in the bag was measured in $20 \mathrm{ml}$ samples. Breath hydrogen volume was calculated for each 30 minute period by multiplying mean breath minute volume $\times 30 \times$ end expiratory breath hydrogen concentration. Mean hydrogen concentration in the gas collection bag used for the measurement of breath minute volume was 7 (SEM 2) ppm, that is, $18 \%$ lower than in the end expiratory breath sample that was obtained immediately after finishing the quantitative breath collection. Breath hydrogen volume calculated with the formula was therefore reduced by $18 \%$ to account for the use of end expiratory hydrogen concentration for the calculations.

\section{Results}

HYDROGEN EXCRETION IN FLATUS

Table II shows mean total flatus volume and flatus hydrogen volume over a six hour period during fasting and after ingestion of lactulose. Figure 1 shows that there was an up to eightfold interindividual difference in cumulative flatus excretion after ingestion of $12.5 \mathrm{~g}$ lactulose. Some of the subjects who ingested $12.5 \mathrm{~g}$ of lactulose produced as much flatus as subjects who ingested double that amount of lactulose, whereas other subjects only produced flatus volumes that were close to the mean flatus volume during fasting. Figures $2 \mathrm{~A}$ and $2 \mathrm{~B}$ show individual data on total flatus volume and flatus hydrogen volume.

\section{HYDROGEN EXCRETION IN BREATH}

Table III shows the results of quantitative breath collections in the four subjects. Mean breath

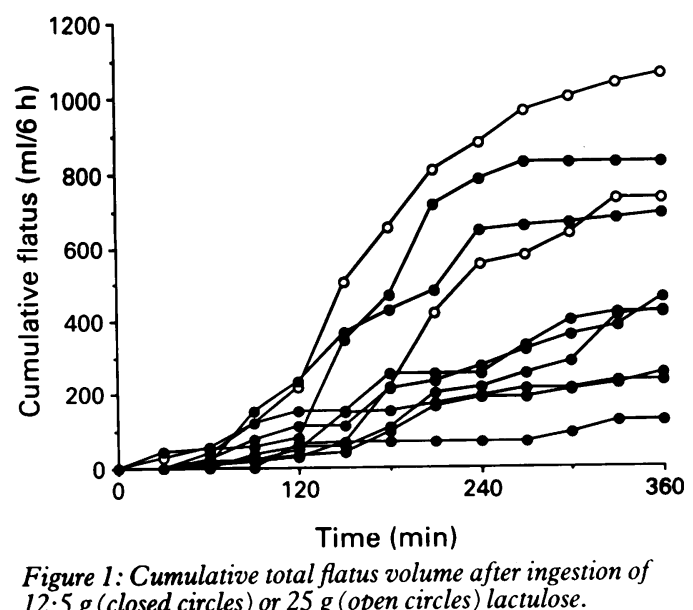

$12.5 \mathrm{~g}$ (closed circles) or $25 \mathrm{~g}$ (open circles) lactulose. 
Figure 2: (A) Hydrogen volume in flatus and breath during fasting and after ingestion of lactulose. The regression line is calculated for the data points that were obtained after ingestion of lactulose. (B) Correlation between total flatus volume and the proportion of hydrogen excreted in breath (as \% of total hydrogen excretion). Closed circles lactulose; open circles fasting.
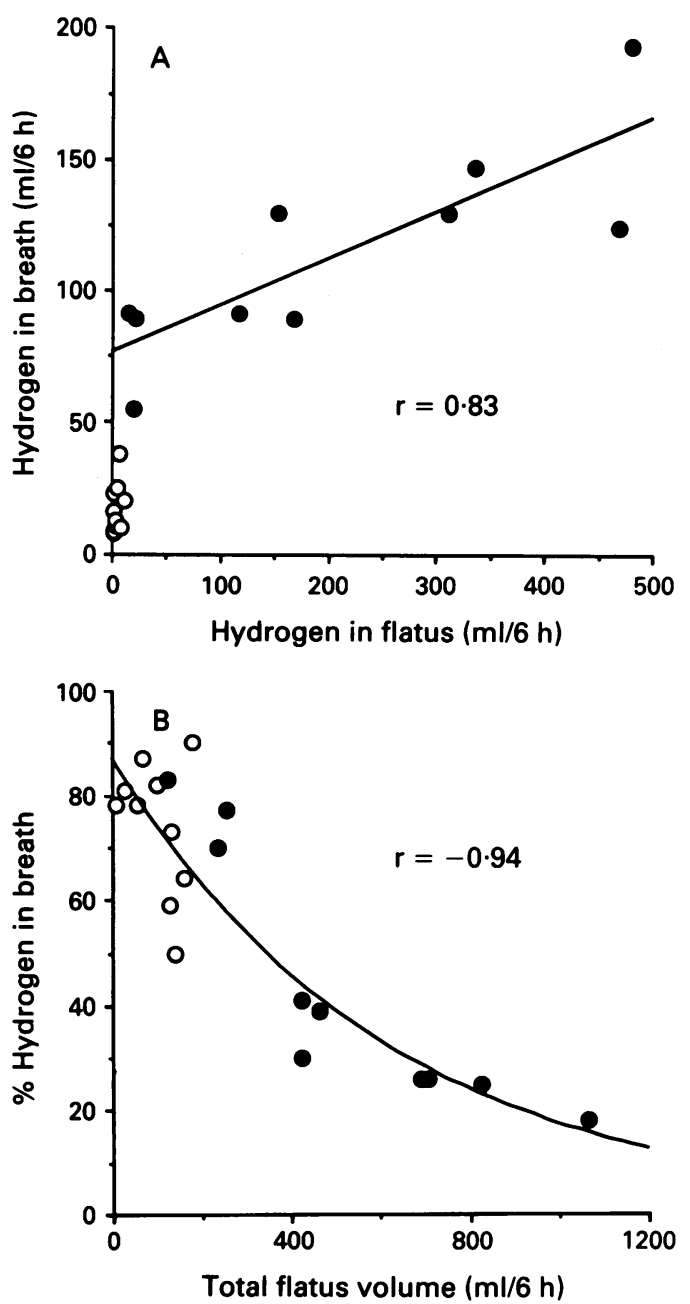

minute volume in the supine position was 6.8 (SEM 0.6) $1 / \mathrm{min}$. Because intrasubject variability $(v=0.08$ to 0.20$)$ and intersubject variability $(v=0 \cdot 2)$ of breath minute volume was low, and, as pointed out in the methods section, mean body surface area in these four subjects was equal to the mean body surface area in all 10 subjects, mean breath minute volume measured in the four subjects was used to calculate breath hydrogen volume in all subjects. Table II shows mean hydrogen volumes in breath during fasting and after ingestion of lactulose. Figure $2 \mathrm{~A}$ shows individual data.

ASSESSMENT OF COLONIC HYDROGEN ABSORPTION As cumulative flatus excretion curves had reached their plateau in most cases six hours after ingestion of lactulose (Fig 1), colonic gas accumulation and excretion of flatus caused by bacterial metabolism of lactulose was considered to be complete by this time. Colonic hydrogen absorption was assessed by correlating hydrogen

TABLE III Results of quantitative breath collections

\begin{tabular}{lllll}
\hline Subject & $\begin{array}{l}\text { Surface } \\
\text { area }\left(m^{2}\right)\end{array}$ & No & $\begin{array}{l}\text { BMV }(\text { l/min }) \\
(\text { mean }(S D))\end{array}$ & $\begin{array}{l}\text { Intraindividual } \\
\text { variability }\end{array}$ \\
\hline GE & 1.57 & 7 & $7.0(1 \cdot 5)$ & 0.20 \\
CP & 2.03 & 3 & $5.0(0.7)$ & 0.14 \\
BM & 1.84 & 3 & $7 \cdot 7(1.6)$ & 0.21 \\
CC & 2.00 & 9 & $8 \cdot 1(0.7)$ & 0.08 \\
\hline
\end{tabular}

No=number of five minute breath ollections; $B M V=$ breath minute volume. volumes in flatus and breath after lactulose ingestion. Figure 2A shows that hydrogen volume in breath after ingestion of lactulose was as high as $175 \mathrm{ml} / 6 \mathrm{~h}$ and correlated positively with hydrogen volume in flatus (regression line for the correlation after ingestion of lactulose: $y=76 \cdot 1+0 \cdot 18 \times, r=0 \cdot 83, p<0 \cdot 01)$. The significance of the positive intercept of the regression line at the $y$ axis is considered later.

The efficiency of colonic hydrogen absorption during periods of low and high colonic gas accumulation rate was assessed by the proportion of hydrogen absorbed in the colon and excreted in breath. Figure 2B shows that the efficiency of colonic hydrogen absorption correlated negatively with total flatus volume (exponential curve fit, $r=-0.94, p<0.001$ ). In our subjects up to $90 \%$ of the total excreted hydrogen volume was excreted in breath when flatus volume was low, and only $20 \%$ when flatus volume was high.

\section{Discussion}

The data show that the efficiency of colonic hydrogen absorption depends on the amount of hydrogen that accumulates in the colon. This has been suggested previously by Christl et al. ${ }^{13}$ Hydrogen excretion rates in flatus during the control period and after lactulose in this study are in line with excretion rates in the study by Christl $e t a l{ }^{13}$ although slightly different doses of lactulose were used. Absorption has a major role in reducing colonic hydrogen volume when gas accumulation rate is low - for example, under control conditions when the main substrate for gas production is presumably endogenous glycoproteins, ${ }^{12}$ - or in subjects who produce only little gas from fermentable carbohydrates that reach the colon.

The positive intercept of the regression line at the $y$ axis (Fig 2A) suggests that colonic hydrogen production only causes colonic hydrogen accumulation, and ultimately excretion of hydrogen in flatus, when a threshold of intracolonic hydrogen volume, which, according to the intercept is $76 \mathrm{ml} / 6 \mathrm{~h}$, is exceeded. If intracolonic hydrogen volume is below this threshold volume, all of it is absorbed and excreted in breath.

Because hydrogen is only a minor component of colonic gas in subjects without carbohydrate malabsorption (Table 1), the threshold for total colonic gas has to be considerably higher. The threshold for total colonic gas volume was calculated with hydrogen as a 'marker gas', and published data on intestinal permeability of gases $^{8}$ and flatus composition. ${ }^{14}$ It has to be kept in mind, that these calculations are speculative and would have to be confirmed by future studies that measure the other main components of colonic gas - namely, carbon dioxide, nitrogen, and, in varying proportions in different populations, also methane.' Nevertheless, these calculations can give an idea of the order of magnitude of the total colonic gas volume absorbed under baseline conditions and the volume which therefore has to be exceeded before any gas is expelled as flatus.

Calculation of the threshold for total colonic gas volume has to take into account factors that 
influence colonic gas absorption, such as the transmucosal pressure gradient and the specific absorptive capacity for various gases. Because hydrogen content of flatus during fasting is $5 \%$, and there is no hydrogen production in the body, ${ }^{3}$ the pressure gradient between the colonic lumen and blood is $38 \mathrm{~mm} \mathrm{Hg}$ (that is, $5 \%$ of $760 \mathrm{~mm} \mathrm{Hg}$, which is ambient air pressure at sea level). For comparison, mean concentration of carbon dioxide in colonic gas during fasting is $14 \%,{ }^{14}$ giving it an intracolonic partial pressure of $106 \mathrm{~mm} \mathrm{Hg}$. The transmucosal pressure gradient for carbon dioxide is therefore $106 \mathrm{~mm}$ $\mathrm{Hg}$ minus $40 \mathrm{~mm} \mathrm{Hg}$ (which is carbon dioxide partial pressure in arterial blood) - that is, $66 \mathrm{~mm}$ $\mathrm{Hg}$. The transmucosal pressure gradient for carbon dioxide absorption, therefore, is almost twice as high as the gradient for hydrogen. Also, specific absorptive capacity for carbon dioxide is about 20 times higher than for hydrogen, ${ }^{8}$ so that under basal conditions during fasting presumably about 40 times more carbon dioxide can be absorbed in the colon. Absorption of hydrogen and carbon dioxide increases the partial pressure of nitrogen in intestinal gas. Therefore, although nitrogen is the least permeable gas in the intestine,${ }^{8}$ it can be assumed that hydrogen and carbon dioxide absorption will also cause a decrease in intracolonic nitrogen volume, be it through increased absorption of nitrogen, or through decreased diffusion of nitrogen from the blood into the colonic lumen.

These calculations suggest that during fasting colonic gas accumulation rate has to exceed $3 \cdot 1$ $1 / 6 \mathrm{~h}$ (this is $76 \mathrm{ml}$ of hydrogen and $40 \times 76 \mathrm{ml}$ of carbon dioxide, not even taking nitrogen and methane into account) before considerable amounts of intracolonic gas accumulate and are excreted as flatus or cause other symptoms related to gas accumulation. If this calculated threshold is compared with the total six hour flatus volume during fasting, which was only $100 \mathrm{ml} / 6 \mathrm{~h}$, the large contribution of colonic gas absorption to the removal of colonic gas during fasting can be appreciated. Theoretically, if the high colonic absorptive capacity for gas under baseline conditions is disturbed, colonic gas could accumulate even without an overt substrate for gas production being present.

In subjects who have colonic flora producing methane, methane production uses 4 moles of hydrogen and 1 mole of carbon dioxide to form 1 mole of methane and 2 moles of water. ${ }^{15}$ The total gas volume is therefore reduced fivefold. Methane is absorbed slowly in the intestine, its specific absorptive capacity being about 40 times lower than for carbon dioxide, and only $60 \%$ of the specific absorptive capacity for hydrogen ${ }^{8}$ In patients who have methane producing bacterial flora the beneficial effect of the reduction in intracolonic gas volume due to gas catabolism therefore is partly antagonised by the production of a gas that is considerably less readily absorbed, although the reduction in gas volume should outweigh the lower gas absorption rate.

The efficiency of colonic hydrogen absorption declines dramatically as colonic gas accumulation rate increases. This may be of clinical relevance in patients who complain of symptoms related to gas - for example, after ingestion of food contain- ing poorly absorbable carbohydrates such as dietary fibres, some of which are readily fermented by colonic bacteria. ${ }^{6}$ When low amounts of lactulose, comparable with the dietary fibre content of a meal," are ingested, the increase in total flatus volume, and also hydrogen volume in flatus is highly variable between individual subjects and can be as high as 1200 $\mathrm{ml} / 6 \mathrm{~h}$. Compared with the increase in hydrogen volume of flatus, the increase in hydrogen volume in breath is considerably smaller (Fig 2A), and the proportion of hydrogen that is absorbed in the colon and excreted in breath declines from $90 \%$, when colonic gas accumulation rate is low, to $20 \%$ when gas accumulation rate is high (Fig 2B). This is presumably due to more rapid emptying of larger volumes of gas, which decreases the time available for absorption of gas. The speed of colonic emptying of gas can be appreciated from the slopes of the cumulative total flatus volume curves (Fig 1). Peak flatus excretion was as high as $300 \mathrm{ml} / 30$ minutes.

A second reason why colonic hydrogen absorption decreases as flatus volume increases may be the decreased surface: volume ratio of larger gas bubbles, which decreases the effective surface area for absorption of gas. A third reason for smaller proportions of gas being absorbed may be a change in intracolonic gas composition and replacement of absorbable gas by a less absorbable gas.

The efficiency of colonic gas absorption should theoretically also be influenced by the fermentability of the substrate. Rapid fermentation, which is the case for lactulose ${ }^{16}$ increases the gas accumulation rate, and therefore decreases the efficiency of colonic gas absorption. By contrast, slower fermentation would decrease colonic gas accumulation rate, thereby making colonic gas absorption more efficient. Also, the fermentation rate might also influence the net volume of gas produced, as it has been shown that hydrogen and methane production vary along the colon ${ }^{17}-$ if fermentation rate is slow, more substrate would presumably reach the left colon, where more methane is produced. Because there are large differences in the fermentability of various kinds of dietary fibres, ${ }^{18}$ efficiency of gas absorption might be influenced by the source of dietary fibres.

After ingestion of $12.5 \mathrm{~g}$ of lactulose there was an eightfold interindividual difference in flatus volume, which may be one reason why some people do and others do not get symptoms due to gas after ingestion of fermentable substrates. Our data suggest that more rapid colonic emptying of gas as flatus is the consequence, rather than the cause of the interindividual differences in colonic gas accumulation, because if faster colonic transit time were the reason for higher flatus volumes, there would be less time available for colonic gas absorption and therefore a negative correlation would be shown in Fig 2A. Although interindividual differences in colonic motor activity may contribute to interindividual differences in flatus volume, it is not likely the major cause of these differences.

Also, the interindividual differences in gas accumulation can neither be due to interindividual differences in colonic gas absorption, 
otherwise there would be a negative correlation in Fig 2A, nor to interindividual differences in the amount of lactulose that was metabolised by bacteria, because all of the ingested lactulose reaches the colon, ${ }^{19}$ and $12.5 \mathrm{~g}$ of lactulose is metabolised completely by colonic bacteria in normal subjects. ${ }^{20}$ Our data therefore suggest that the interindividual differences in colonic gas accumulation are most likely due to differences in bacterial production or catabolism of gas.

In conclusion, the results show that: (1) the colonic gas accumulation rate after ingestion of poorly absorbable carbohydrates has high interindividual variability, which may be one explanation for the differences in side effects reported by patients ingesting diets that have a high content of fermentable dietary fibres; (2) when colonic gas accumulation rate is low, gas absorption reduces colonic gas volume very efficiently, suggesting that diseases which impair this efficient gas absorption can cause symptoms related to intestinal gas accumulation even if there is no overt source for gas production; (3) when gas accumulation rate is high, colonic gas absorption is ineffective, so that the patients who produce more gas after ingestion of fibres, get the second disadvantage of absorbing a smaller fraction of gas; and (4) the interindividual differences in colonic gas accumulation are primarily caused by interindividual differences in colonic bacterial metabolism and not by colonic gas absorption or colonic gas transit time. This suggests that future therapeutic approaches to this clinically important problem should be directed towards interfering with colonic bacterial metabolism.

I was supported by Öster Ges f Ernährungsforschung. I thank John S Fordtran MD for assistance with designing the experiment and Carol and Dina Santa Ana for technical assistance.
1 Levitt MD, Bond JH. Intestinal gas. In: Sleisenger $M H$, Fordtran JS, eds. Gastrointestinal disease. 4th ed. Philadelphia, Pennsylvania: WB Saunders Company, 1989; 257-63.

2 Miller TL, Wolin MJ. Fermentations by saccharolytic intestinal bacteria. Am f Clin Nutr 1979; 32: 164-72.

3 Levitt MD. Production and excretion of hydrogen gas in man. New Engl f Med 1969; 281: 122-7.

4 Hammer HF. Fine KD, Santa Ana CA, Porter JL, Schiller LR, Fordtran JS. Carbohydrate malabsorption: Its measurement and its contribution to diarrhea. $\mathcal{F}$ Clin Invest 1990; 86: 1936-44.

5 Flourie B, Florent C, Etanchaud F, Evard D, Franchisseur C, Rambaud JC. Starch absorption by healthy man evaluated by lactulose hydrogen breath test. Am $\mathcal{F}$ Clin Nutr 1988; 47: 61-6.

6 Cummings JH, Stephen AM. The role of dietary fibers in the human colon. Can Med Assoc fournal 1980; 123: 1109-14.

7 Bjorneklett A, Jenssen E. Measurement of pulmonary hydrogen and hydrogen diffusion from small bowel and the colon. Scand 7 Gastroenterol 1980; 15: 817-23.

8 McIver MA, Redfield AC, Benedict EB. Gaseous exchange between the blood and the lumen of stomach and intestines. Am F P hysiol 1926; 76: 92-111.

9 Hammer HF, Sheikh MS, Colonic gas absorption in induced carbohydrate malabsorption - effect of simethicone. Eur $\mathcal{F}$ Gastroenterol Hepatol 1992; 4: 141-5.

10 Connor WE. Dietary fiber - nostrum of critical nutrient? $N$ Engl f Med 1990; 322: 193-5.

11 Swain JF, Rouse IL, Curley CB, Sacks FM. Comparison of the effect of oat bran and low-fiber wheat on serum lipoprotein levels and blood pressure. N Engl F Med 1990; 322: 147-52.

12 Perman JA, Modler S. Glycoproteins as substrates for production of hydrogen and methane by colonic bacterial flora. Gastroenterology 1982; 83: 388-93.

13 Christl SU, Murgatroyd PR, Gibson GR, Cummings JH. Production, metabolism, and excretion of hydrogen in the large intestine. Gastroenterology 1992; 102: 1269-77.

14 Kirk E. The quantity and composition of human colonic flatus. Gastroenterology 1949; 12: 782-94.

15 Gibson GR, Cummings JH, Macfarlane GT, Allison C, Segal I, Vorster HH, Walker ARP. Alternative pathways for I, Vorster HH, Walker ARP. Alternative pathways for Gut 1990; 31: 679-83.

16 Bown RL, Gibson JA, Sladen GE, Hicks B, Dawson AM. Effects of lactulose and other laxatives on ileal and colonic $\mathrm{pH}$ as measured by a radiotelemetry device. Gut 1974; 15: 999-1004.

17 Flourie B, Etanchaud F, Florent C, Pellier P, Bouhnik Y, Rambaud JC. Comparative study of hydrogen and methane production in the human colon using caecal and faecal homogenates. Gut 1990; 31: 684-5.

18 Fleming SE, Marthinsen D, Kuhnlein H. Colonic function and fermentation in men consuming high fiber diets. $\mathcal{F} \mathrm{Nutr}$ 1983; 113: 2535-44.

19 Menzies IS, Laker MF, Pounder R, Bull J, Heyer S, Wheeler PG, Creamer B. Abnormal intestinal permeability to sugars in villous atrophy. Lancet 1979; ii: 1107-9.

20 Hammer HF, Santa Ana CA, Schiller LR, Fordtran JS Studies of osmotic diarrhea induced in normal subjects by ingestion of polyethylene glycol and lactulose. $\mathcal{F}$ Clin Inves 1989; 84: 1056-62. 